
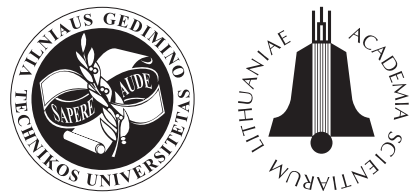

TRANSPORT

2010

25(2): 129-137

\title{
MODELLING HETEROGENEOUS TRAFFIC FLOW ON UPGRADES OF INTERCITY ROADS
}

\author{
Venkatachalam Thamizh Arasan ${ }^{1}$, Shriniwas Shrikant Arkatkar ${ }^{2}$ \\ Dept of Civil Engineering, Transportation Engineering Division, \\ Indian Institute of Technology Madras, Chennai - 600 036, India \\ E-mails: ${ }^{1}$ arasan@iitm.ac.in; ${ }^{2}$ s_arkatkar@yahoo.co.in
}

Received 12 September 2009; accepted 20 May 2010

\begin{abstract}
The effect of an upgrade and its length is very significant for traffic flow characteristics. Road traffic in developing countries like India is highly heterogeneous comprising vehicles of wide ranging physical dimensions, weight and dynamic characteristics such as engine power, acceleration rate, etc. Due to these variations, the effect of grade on vehicles in heterogeneous traffic may vary significantly among vehicle categories. Variation in the level of the interaction between vehicles on upgrades may result in different sets of traffic flow characteristics. Hence, it is necessary to model traffic flow on upgrades and study, in depth, changes in traffic flow characteristics with alteration in the magnitude of an upgrade and its length. Computer simulation has emerged as an effective technique for modelling traffic flow due to its capability to account for randomness related to traffic. This study is concerned with applying a simulation model of heterogeneous traffic flow, named HETEROSIM, to study the traffic flow characteristics and performance of different vehicle types on upgrades of different magnitudes.
\end{abstract}

Keywords: upgrade, power-to-weight ratio, acceleration rates, heterogeneous traffic, simulation, speed-volume relationships, speed-distance profiles.

\section{Introduction}

Knowledge of traffic flow characteristics is very important for planning, analyzing, designing and operating roadway systems (Helbing and Greiner 1997; Arasan and Koshy 2005; Kerner and Klenov 2006; Berezhnoy et al. 2007; Bonzani 2007; Jakimavičius and Burinskienè 2007, 2009; Junevičius and Bogdevičius 2007, 2009; Akgüngör 2008a, 2008b; Bazaras et al. 2008; Gowri and Sivanandan 2008; Yousefi and Fathy 2008; Antov et al. 2009; Beljatynskij et al. 2009; Gražulevičienė and Bendokienè 2009). Roadway capacity values and speed-flow relationships used for planning, designing and operating roads, in most of the developed countries, pertain to fairly homogeneous traffic conditions comprising vehicles of more or less uniform static and dynamic characteristics. However, traffic scenario in developing countries like India differs significantly from conditions observed in developed countries. Road traffic in India is highly heterogeneous comprising vehicles of wide ranging physical dimensions, weight and dynamic characteristics.

Different types of vehicles of heterogeneous traffic on Indian roads may be broadly grouped into the following categories:

1. buses;
2. trucks;

3. light commercial vehicles comprising large vans and small trucks;

4. cars including jeeps and small vans;

5. motorised three-wheelers, including threewheeled motorised vehicles to carry passengers and three wheeled motorised vehicles to carry small quantities of goods;

6. motorised two-wheelers, including motorcycles, scooters and mopeds;

7. bicycles;

8. tricycles to carry passengers or small quantities of goods;

9. animal drawn vehicles.

These motorised and non-motorised vehicles share the same road space without any physical segregation. To manoeuvre, these vehicles take any lateral position on the roadway based on space availability. When such different types of vehicles with varying static and dynamic characteristics are allowed to mix and move on the same roadway facility, from time to time, a variable set of longitudinal and transverse distributions of vehicles may be noticed.

The effect of grade and its length is very significant for traffic flow characteristics. On upgrades, heavy vehi- 
cles such as trucks, buses, etc. will experience significant reduction in their speeds, whereas passenger cars and other smaller vehicles such as motorized-two-wheelers may experience relatively lesser speed reduction. Under heterogeneous traffic conditions, this variation in speed reduction among different vehicle categories can be attributed to their wide ranging physical characteristics such as dimensions, weight, etc. as well as to their dynamic characteristics such as engine power, acceleration rate, etc. Variation in the level of the interaction between vehicles on upgrades may result in a different set of traffic-flow characteristics when compared with traffic flow characteristics on level roads. Hence, it is necessary to model traffic flow on upgrades and to study changes in traffic flow characteristics with changes in the magnitude of an upgrade and its length. Simulation, from microscopic through macroscopic, is increasingly becoming a popular traffic-flow modeling tool for analyzing various traffic operations and vehicular interactions. Research work reported in this paper is related to the study on the effect of an upgrade and its length on the performance of different vehicle categories under heterogeneous traffic conditions. The methodology adopted for modelling heterogeneous traffic flow on roads having upgrades of different magnitudes, the details of analysis and relevant results along with a review of the previous studies are presented in the following sections.

\section{Review of the Previous Studies}

In the past, researchers used a force balance equation and vehicle mechanics for developing models predicting truck speeds on upgrades of any percentage and length.

The impact of road gradient on speed was analyzed by Yagar and Aerde (1983) who found that the operating speed at a location is expected to decrease by approximately $1.8 \mathrm{~km} / \mathrm{h}$ for each $1 \%$ of grade when going uphill.

Gillespie (1985) developed a simplified means of predicting truck hill-climbing performance based on the characterization of the available power for accelerating and overcoming grade. The author also found that the ratio of the available power to weight is speed dependent but provides an easy means for calculating truck speed profiles on arbitrary grades.

Archilla and Fernandez De Cieza (1996) developed truck speed profiles on different grades. The simple force balance equation was fitted to the field data. The model explained about $80 \%$ of the observed variation. For developing speed profiles on grades, the weight-to-power ratio of $190 \mathrm{~kg} / \mathrm{kW}$ was considered.

Bester (2000) developed a procedure for calculating speed profiles of trucks by using the assumption that the acceleration of a truck was a linear function of speed.

A Policy on Geometric Design ... (2004) provides a single set of speed profiles over distance to characterize the deceleration and acceleration of typical heavy trucks based on the weight-to-power ratio of $120 \mathrm{~kg} / \mathrm{kW}$ on different grades.

Bennett and Greenwood (2001) as a part of Highway Development and Management series, popularly known as HDM-IV manual, has given the governing equation for the forward movement of a road vehicle, when the latter encounters a grade. The manual has also given the values of different parameters that can be used for estimating the magnitude of resistance (air resistance, rolling resistance, grade resistance, etc.) involved in the forward movement of vehicle on grades.

Lucic (2001) extended the vehicle-dynamics model by introducing the concept of variable power in order to capture the buildup of power as the vehicle engages in gearshifts. The proposed extension has resulted in the significant enhancement of the state-of-the-art vehicledynamics model. The author finally concluded that the use of constant transmission efficiency results in an overestimation of vehicle speeds at low speeds and an underestimation at high speeds.

Lan and Menendez (2003) developed a well-defined speed profile for trucks based on dynamic, kinematic and operating characteristics of moving trucks on grades. For developing speed profiles on grades, the weight-to-power ratios of $121.7 \mathrm{~kg} / \mathrm{kW}$ and $182.5 \mathrm{~kg} / \mathrm{kW}$ were considered. The exact speed-profile model was derived through numerical integration. The authors also described an approximation model suiTable for calculation by hand. All these studies, however, are mainly related to the characterization of truck performance on upgrades under homogeneous traffic conditions and hence, the results of these studies are not applicable for Indian conditions.

A review of Indian studies related to the traffic flow characteristics of grades proposed that there had been only one study on the subject matter.

Chandra and Goyal (2001) measured a free speed of different types of vehicles on two-lane intercity roads having grades with different magnitudes. The analysis pertaining to the average change in the free speed of different types of vehicles with a grade indicated that each percent of an upgrade decreases the free speed of a car by $2.96 \mathrm{~km} / \mathrm{h}$, that of a bus by $2.43 \mathrm{~km} / \mathrm{h}$, motorised twowheelers - by $2.50 \mathrm{~km} / \mathrm{h}$, light commercial vehicles - by $1.26 \mathrm{~km} / \mathrm{h}$, a tractor with trailer - by $2.06 \mathrm{~km} / \mathrm{h}$, a bicycle - by $0.51 \mathrm{~km} / \mathrm{h}$, a cycle-rickshaw - by $0.36 \mathrm{~km} / \mathrm{h}$ and an animal drawn vehicle - by $0.19 \mathrm{~km} / \mathrm{h}$. Finally, the authors concluded that the free speed of a vehicle decreases uniformly with an increase in a gradient. The actual amount of reduction depends upon the type of a vehicle and the magnitude of the gradient.

The literature survey clearly shows that, at present, there is no ready-to-use reference material available regarding developing speed-distance profiles for different vehicles on grades of varying magnitudes under heterogeneous traffic conditions in India. Hence, there is a need to model vehicular movement on grades at micro-level, which may enable researchers to study traffic flow characteristics with variation in the magnitude of a grade and its length and to develop speed-distance profiles of different vehicle categories for upgrades of magnitude varying over a wider range. 


\section{Objective and Scope}

The general objective of research work reported here is to study the effect of upgrades of different magnitudes on traffic flow characteristics and to develop speed-distance profiles (performance curves) for different categories of vehicles under heterogeneous traffic conditions.

The recently developed micro-simulation model of heterogeneous traffic-flow HETEROSIM (Arasan and Koshy 2005) is used to study traffic flow characteristics at micro-level over a wide range of traffic flow conditions on upgrades.

Field data collected on traffic flow characteristics such as free speed, physical dimensions of different vehicle types, lateral clearance between vehicles, etc. are used in the calibration and validation of the simulation model.

Acceleration rates over different speed ranges required for the simulation of the heterogeneous traffic flow of grades were estimated for different upgrades.

The validated simulation model is then used to develop speed-volume relationships for upgrades of different magnitudes.

Speed-distance profiles are also developed for different vehicle categories for upgrades of different magnitudes using the simulation model.

\section{The Simulation Model}

As this study pertains to heterogeneous traffic conditions prevailing in India, the available traffic simulation models based on homogeneous traffic conditions where a clear lane and queue discipline exist are not applicable to study heterogeneous traffic flow characteristics.

Also, the models developed through research attempts made to model heterogeneous traffic flow (Khan and Maini 2000; Kumar and Rao 1996; Ramanayya 1988) are limited in scope and do not address all aspects comprehensively.

The recently developed model of heterogeneous traffic flow HETEROSIM (Arasan and Koshy 2005), however, is comprehensive and capable of replicating heterogeneous traffic flow.

The modeling framework is explained briefly here to provide the background to the study. For the purpose of simulation, the entire road space is considered as a single unit and vehicles are represented as rectangular blocks on road space, the length and breadth of which represent the overall length and the overall breadth of the vehicles respectively. The front left corner of the rectangular block is taken as the reference point and the position of vehicles on road space is identified based on the coordinates of the reference point with respect to origin chosen at a convenient location on the space. The simulation model uses the interval scanning technique with a fixed increment in time. For the purpose of simulation, the length of road stretch as well as road width can be varied as per user specification.

The model was implemented in the $C++$ programming language with modular software design.
The simulation process consists of the following major sequential steps related to traffic flow on the midblock sections of roads:

1. vehicle generation;

2. vehicle placement;

3. vehicle movement.

The snapshot of the animation of heterogeneous traffic flow obtained using the animation module HETEROSIM is shown in Fig. 1.

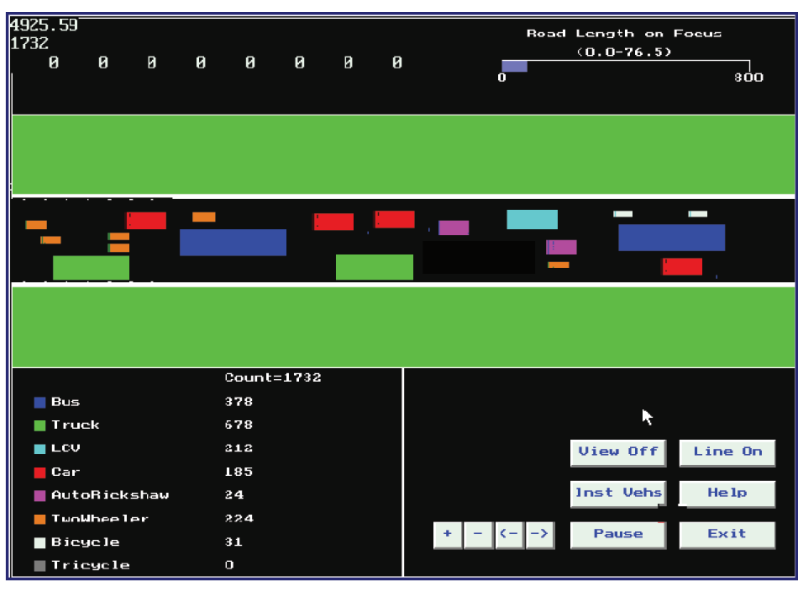

Fig. 1. Snapshot of the animation of the simulated heterogeneous traffic flow

\section{Model Validation}

When used for studying the effect of grade, the simulation model HETEROSIM requires data particularly on the free-flow speeds of different vehicle types at the start of the sections and acceleration rates of different vehicle categories while negotiating a particular gradient, in addition to other relevant data pertaining to the roadway and traffic conditions.

Hence, for the purpose of data collection, study stretches were selected after conducting a reconnaissance survey to satisfy the following conditions:

1. the stretch should have a uniform gradient for considerable length;

2. the stretch should be fairly straight;

3. the width of the roadway should be uniform;

4. there should not be any direct access from the adjoining land used on both sides.

The three study stretches selected for data collection are on National Highway No. 4 near Pune, in Maharashtra (Western part of India) and their specific locations are:

1. between $\mathrm{km} 31.2$ and $\mathrm{km} 31.5$ with a gradient of $3 \%$;

2. between $\mathrm{km} 2.6$ and $\mathrm{km} 3.0$ with a gradient of $3.78 \%$;

3. between $\mathrm{km} 5.2$ and $\mathrm{km} 5.9$ with a gradient of $5 \%$.

The selected stretches are four lane divided roads with a total carriageway width of $8.75 \mathrm{~m}$ (including shoulder) for each direction of traffic flow. Thus, there was a need to estimate acceleration rate for different cat- 
egories of vehicles, for a set of speed ranges and for three observed grades of $3 \%, 3.78 \%$ and $5 \%$. Free speed data on different categories of vehicles were measured at the initial positions of the chosen sections of different grades. The model was validated for all three grades mentioned above. In this paper, the results pertaining to the validation of 5\% upgrade are presented, as an example.

\section{Estimation of Acceleration Rates}

The thrust required for the forward movement of a road vehicle is determined by the summation of forces acting on the vehicle in the longitudinal direction.

The forces acting on the vehicle while negotiating an upgrade of magnitude $i \%$ are:

1) rolling resistance;

2) air resistance;

3) grade resistance;

4) inertial forces

5) during acceleration and deceleration, as shown in Fig. 2.

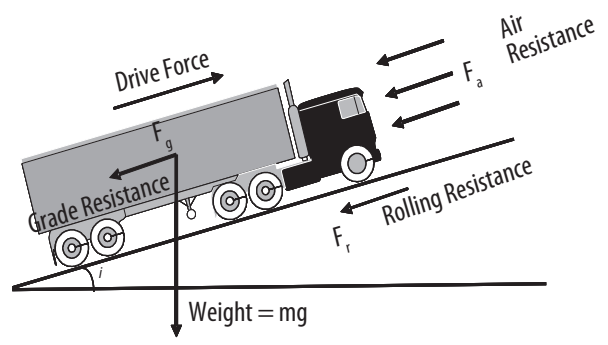

Fig. 2. Forces acting on a moving vehicle on upgrades

Propulsive effort (drive force) is derived from the engine to overcome these forces. Any reserve in drive force, if available, may be used either to accelerate the vehicle or to overcome the drag arising from upgrades. When encountering a grade requiring thrust greater than the available drive force, deficiency is made up by the deceleration of the vehicle. The speed at which the available drive force is zero represents the steady-state or terminal or 'crawl' speed of the vehicle. This steady-state speed that a vehicle can maintain on an upgrade occurs when forces are in balance. The following (Equation 1) is the fundamental equation of motion for a road vehicle (Bennett and Greenwood 2001):

$$
a=\frac{1000 \cdot P_{d}}{M \cdot E M R A T} \frac{1}{v}-\frac{1}{M \cdot E M R A T}\left(F_{a}+F_{r}+F_{g}\right),
$$

where: $a$ - acceleration, $\mathrm{m} / \mathrm{s}^{2} ; P_{d}$ - driving power delivered to wheels, $\mathrm{kW} ; M$ - vehicle mass; EMRAT - effective mass ratio; $F_{a}$ - aerodynamic drag resistance, $\mathrm{N}$; $F_{r}$ - rolling resistance, $\mathrm{N} ; F_{g}-$ gradient resistance, $\mathrm{N}$; $\mathrm{v}$ - vehicle speed, $\mathrm{m} / \mathrm{s}$.

The equation used for calculating aerodynamic drag resistance is as follows:

$$
F_{a}=0.5 \cdot \rho \cdot C D \cdot C D m u l t \cdot A F \cdot v^{2},
$$

where: $F_{a}$ - aerodynamic force opposing the motion of the vehicle; $\rho$ - mass density of the air, $\mathrm{kg} / \mathrm{m}^{3}$ $\left(1.2 \mathrm{~kg} / \mathrm{m}^{3}\right) ; C D$ - aerodynamic drag coefficient; $C D$ mult - aerodynamic drag coefficient multiplier; $A F$ - the projected frontal area of the vehicle, $\mathrm{m}^{2} ; v$ - the speed of the vehicle, $\mathrm{m} / \mathrm{s}$.

The equation used for calculating rolling resistance is as follows:

$$
F_{r}=M \cdot f \cdot g
$$

where: $F_{r}$ - rolling resistance, $\mathrm{N} ; M$ - the mass of the vehicle, $\mathrm{kg} ; f$ - the coefficient of rolling resistance (0.01).

The value of the coefficient of rolling resistance $(f)$ is approximately constant up to the speed of $50 \mathrm{~km} / \mathrm{h}$ (Kadiyali et al. 1982). At higher speeds (more than $50 \mathrm{~km} / \mathrm{h}$ ), the values can be approximately calculated as:

$$
f=f_{o}(1+0.01(v-50)),
$$

where: $f$ - the coefficient of rolling resistance at speed $v$; $v$ - speed in $\mathrm{km} / \mathrm{h} ; f_{o}$ - the coefficient of rolling resistance assumed constant up to a speed of $50 \mathrm{~km} / \mathrm{h}$.

The equation used for calculating grade resistance is given as follows:

$$
F_{g}=\frac{M i g}{100}
$$

where: $F_{g}$ - gradient resistance, $\mathrm{N} ; M$ - the mass of the vehicle, $\mathrm{kg} ; i$ - the magnitude of the gradient in percentage.

Equation (1) indicates that the ability of a vehicle to accelerate on an upgrade is dependent on the used power-to-weight ratio, the mass and various forces opposing motion. Vehicles with low power-to-weight ratios such as trucks, while negotiating up grades, may decelerate to a crawl or terminal speed where forces are in balance and acceleration is equal to zero. This steady-state terminal speed can, thus, be obtained by solving Equation (1) for the velocity term. Hence, the data pertaining to maximum power $(\mathrm{kW})$ and gross vehicle weight $(\mathrm{kg})$ of different makes, for each vehicle category, was collected from the manufacturers' websites, brochures, etc. Finally, the average representative values of power and weight for each vehicle category were arrived at for calculating acceleration rates at various speed ranges. The values pertaining to the coefficient of drag $(C D), C D$ multiplier $(C D m u l t)$, and the projected frontal area (AF), for each vehicle category, were taken from the manual of Highway Development and Management (HDM-4) (Bennett and Greenwood 2001). CD is a function of the direction of vehicle movement relative to wind direction. The apparent direction of the wind, which is the vector resultant of vehicle-movement direction and wind direction, is termed the yaw angle $(\Psi)$. The values of $C D$ reported in literature are usually from wind tunnel tests conducted with a zero degree yaw (i. e. front on to the wind) and accordingly, are the minimum for the vehicle. Hence, to obtain typical values of $C D$ that would be found on roads, it is necessary to adjust to the variation in wind direction which can be achieved using a 'typical' wind angle increasing zero degree-yaw $C D$ leading to wind av- 
eraged $C D$ or $C D(\Psi)$. The ratio of $C D(\Psi)$ divided by $C D$ is termed $C D$ multiplier (CDmult). The Effective Mass RATio (EMRAT) for each vehicle category is also calculated at various speeds as per the guidelines of HDM-4 manual (Bennett and Greenwood 2001). The coefficient of rolling resistance $(f)$ is taken as 0.01 (Kadilyali et al. 1982) as the pavement surface of the study stretch is made of asphaltic concrete. For calculating used driving power delivered to the wheels $\left(P_{d}\right)$, the variable 'power factor' is used. The calculation of the variable 'power factor' involves finding speed at which vehicle power reaches its maximum. For this purpose, a steady state or terminal speed for each vehicle category, at which the vehicle power reaches its maximum, is calculated considering acceleration, $a=0$ in Equation (1). Then, the ratio of vehicle speed under consideration and maximum speed at which vehicle-power attains its maximum is considered as the variable 'power factor'. The used driving power $\left(P_{d}\right)$, then, can be estimated by multiplying the maximum power value by the variable power factor. Thus, using all these parameters acceleration rates at various speed ranges with respect to each upgrade considered for the study, are calculated for different vehicle categories. Acceleration rates, thus estimated over different speed ranges, used as the input to the simulation model, for model validation on a grade of $5 \%$ are given in Table 1 .

Table 1 shows that acceleration rates of such types of vehicles as buses, trucks, light commercial vehicles and motorised three-wheelers, in the speed range of more than $40 \mathrm{~km} / \mathrm{h}$, are negative. The reason behind these negative values can be explained as follows. Force balance Equation (1) consists of two components; namely, drive force derived based on the engine power of the vehicle and types of resistance (air, rolling and grade) to be overcome by a moving vehicle. The propulsive effort (drive force) is derived from the engine (based on the power of the vehicle) to overcome these forces. Any reserve in drive force, if available, may be used either to accelerate the vehicle or to overcome the drag arising from upgrades. When encountering a grade of certain magnitude requiring thrust that is greater than the available drive force (a magnitude of resistance is higher than drive force generated from the engine of the vehicle), deficiency is made up by the deceleration of the vehicle.

Table 1. Estimated acceleration rates on 5\% upgrade

\begin{tabular}{lccc}
\hline \multirow{2}{*}{ Vehicle type } & \multicolumn{3}{c}{$\begin{array}{c}\text { Estimated acceleration rates at various speed } \\
\text { ranges }\left(\mathrm{m} / \mathrm{s}^{2}\right)\end{array}$} \\
\cline { 2 - 4 } & $0-20 \mathrm{~km} / \mathrm{h}$ & $20-40 \mathrm{~km} / \mathrm{h}$ & above $40 \mathrm{~km} / \mathrm{h}$ \\
\hline Buses & 0.08 & 0.05 & -0.21 \\
Trucks & 0.06 & 0.02 & -0.25 \\
L.C.V. & 0.07 & 0.06 & -0.07 \\
Cars & 0.38 & 0.38 & 0.35 \\
M.Th.W & 0.70 & 0.60 & 0.35 \\
M.T.W & 0.11 & 0.03 & -0.20 \\
\hline
\end{tabular}

L.C.V. - Light Commercial Vehicles; M.Th.W. - Motorised ThreeWheelers; M.T.W. - Motorised Two-Wheelers
On upgrades, traffic flow characteristics (the speed of vehicles) will change as its length increases. So, in the case of upgrades, for the purpose of model validation, it is important to compare simulation-output values with the corresponding observed values at different sections on the stretch of roads with a gradient. Therefore, it is necessary to collect traffic-flow data for a particular upgrade at different intervals of the length of an upgrade selected for model validation. Data on traffic required for the study were collected using video recording of traffic flow at the selected locations. Traffic flow was recorded for one hour using a video camera mounted on an adjoining elevated ground, which enabled recording all traffic flow characteristics. Traffic flow was captured at each of the chosen locations (on 5\% upgrade at: $\mathrm{km}$ $5.200, \mathrm{~km} 5.500, \mathrm{~km} 5.700$ and $\mathrm{km} 5.900$ ). The video captured traffic data on all locations and then transferred it to a Work Station (computer) for detailed analysis. The inputs required for the model to simulate heterogeneous traffic flow include road geometry, traffic volume and composition, vehicle dimensions, minimum and maximum lateral spacing between vehicles, minimum longitudinal spacing between vehicles, free speeds of different types of vehicles, acceleration and deceleration characteristics of vehicles, the type of headway distribution and the simulation period. The required input traffic data was obtained by running the video of traffic flow at a slower speed ( $18^{\text {th }}$ of the actual speed) to enable one person to record data observing the details displayed on the monitor of the computer. Traffic composition, for the measured total traffic volume of 598 vehicles per hour, at the starting point of the study stretch with $5 \%$ upgrade, was noted. It was found that Animal drawn vehicles, bicycles and tricycles which might be present in small numbers in certain intercity roads, were not present at any of the study stretches (as these vehicles may not be able to negotiate such steep grades). Similarly, using the same data extraction technique, the observed traffic volume and composition at all other locations for each of the grades were also recorded. It was observed that for each of the grades there was no significant difference in traffic volume and composition obtained from traffic flows passing through various locations of a particular grade. The overall dimensions of all categories of vehicles and the minimum and maximum values of lateral-clearance share (corresponding to, respectively, zero speed and free speed conditions of respective vehicles) were adopted from an earlier study (Arasan and Koshy 2005).

For the purpose of model validation, it was decided to compare the observed and simulated speeds of different categories of vehicles at fixed intervals when the vehicles negotiated for a particular upgrade. Road length on $5 \%$ upgrade was $700 \mathrm{~m}$. The total width of the roadway available for one direction of movement on the divided highway was $8.75 \mathrm{~m}$. For the purpose of validation, for a grade of $5 \%$, simulation was run with three random number seeds and the averages of the three runs were taken as the final output of the model. The observed roadway condition, measured free speed param- 
eters at the initial position, observed traffic volume and composition and acceleration rates (estimated at various speed ranges) were given as the input to the simulation model. The inter-arrival time (headway) of vehicles was found to fit into negative exponential distribution and free speeds of different categories of vehicles based on the results of an earlier study (Kadiyali et al. 1981) were assumed to follow normal distribution. These distributions, then, formed the basis for an input of two parameters for the purpose of simulation. The speeds maintained by different categories of vehicles at the selected sections on the study stretches were obtained as simulation output. A comparison of the observed and simulated speeds maintained by different types of vehicles at three selected sections on 5\% upgrade (km 5200 to $\mathrm{km} 5500(300 \mathrm{~m}), \mathrm{km} 5200$ to $\mathrm{km} 5700(500 \mathrm{~m})$ and $\mathrm{km} 5200$ to $\mathrm{km} 5900(700 \mathrm{~m}))$, namely, sections I, II and III are shown in Table 2 indicating that the simulated speed values significantly match with the field observed speeds for all vehicle types at all selected sections. A statistical validation of the model based on the observed and simulated speeds of different categories of vehicles was also done through the paired $t$-test for 5 degrees of freedom at the level of significance of 0.05 . The calculated t-statistic values for sections I, II and III on 5\% upgrade are $1.23,0.343$ and 0.862 respectively, against the Table value of 2.57 . It can be seen that the value of $t$ statistic calculated based on the observed data is less than the corresponding Table value. This implies that there is no significant difference between the simulated and observed mean speeds at all sections indicating the validity of the simulation model.

\section{Model Application}

The HETEROSIM model can be applied to study various heterogeneous traffic scenarios under varying traffic and roadway conditions. Here, the application of the model is to develop relationship between traffic volume and speed under varying roadway conditions (four-lane divided roads with upgrades varying from $2 \%$ to $6 \%$ ). Further, the validated simulation model is also used to develop speed-distance profiles on upgrades for different vehicle categories under heterogeneous traffic conditions.

\subsection{Development of Speed-Flow Relationships}

Since research work reported here is aimed at studying the effect of an upgrade and its length on traffic flow characteristics and also on the performance of different categories of vehicles in heterogeneous traffic, a four-lane divided road with $8.75 \mathrm{~m}$ of road space (main roadway plus shoulder) available for each direction of movement with a magnitude of upgrades of $2 \%, 3 \%, 4 \%, 5 \%$ and $6 \%$, were considered for model application. For this purpose, a representative traffic composition was considered for simulating traffic flow on the upgrades. This representative traffic composition commonly seen on divided intercity roads in India consists of buses (21\%), trucks (35\%), light commercial vehicles (11\%), cars (17\%), motorised three-wheelers (3\%) and motorised two-wheelers (13\%). The input data on free speed, at the initial position required for simulating traffic flow on grades, was collected on the stretch between $\mathrm{km} 77.2$ and $\mathrm{km} 77.4$ of National Highway No. 45 near Chennai (Southern part of India) which is a four-lane divided road (total width for one direction makes $8.75 \mathrm{~m}$ ). The stretch is straight and level with no side road connections. Also, traffic flow on the study stretch was unhindered by road side land uses. By giving free speeds as input at the entry position of road stretch considered for simulating traffic flow on upgrades, it was possible to model the movement of vehicles approaching an upgrade of the given magnitude from level roads. Acceleration rates over different speed ranges required for the simulation of heterogeneous traffic flow on grades were estimated for different upgrades of a magnitude varying from $2 \%$ to $6 \%$ using equation (1) as explained earlier. The length of road stretch (used for noting outputs) considered for simulation was $1600 \mathrm{~m}$.

Giving relevant data as input, traffic flow on different upgrades was simulated for volume levels ranging from a very low level to the maximum possible value (capacity) and speeds corresponding to each of the volume levels were obtained as output. In this regard, it may be noted that when simulation runs are made with successive increments in the traffic volume (input), there will be a commensurate increase in the exit volume at the end of simulation stretch. When the volume reaches capacity level, the increments in the input traffic volumes

Table 2. Model validation by a comparison of speeds on different sections of $5 \%$ upgrade

\begin{tabular}{lcccccc}
\hline \multirow{2}{*}{$\begin{array}{c}\text { Vehicle } \\
\text { type }\end{array}$} & \multicolumn{2}{c}{ Section I } & \multicolumn{2}{c}{ Section II } & \multicolumn{2}{c}{ Section III } \\
\cline { 2 - 7 } & $\begin{array}{c}\text { Average observed } \\
\text { speed }\end{array}$ & $\begin{array}{c}\text { Average } \\
\text { simulated speed }\end{array}$ & $\begin{array}{c}\text { Average observed } \\
\text { speed }\end{array}$ & $\begin{array}{c}\text { Average simulated } \\
\text { speed }\end{array}$ & $\begin{array}{c}\text { Average } \\
\text { observed speed }\end{array}$ & $\begin{array}{c}\text { Average } \\
\text { simulated speed }\end{array}$ \\
\hline Buses & 40.13 & 37.96 & 37.67 & 35.98 & 35.05 & 34.74 \\
Trucks & 34.37 & 33.22 & 31.38 & 31.87 & 30.05 & 30.52 \\
L.C.V. & 43.62 & 42.96 & 41.89 & 41.34 & 40.07 & 40.35 \\
Cars & 64.82 & 64.00 & 63.23 & 61.91 & 60.95 & 59.86 \\
M.Th.W & 33.09 & 33.40 & 32.35 & 33.12 & 31.86 & 33.06 \\
M.T.W & 48.78 & 49.85 & 48.16 & 49.45 & 47.49 & 48.93 \\
\hline
\end{tabular}

L.C.V. - Light Commercial Vehicles; M.Th.W. - Motorised Three-Wheelers; M.T.W. -Motorised Two-Wheelers 
may not result in the same amount of an increase in the exit volume resulting in a decrease in the rate of traffic flow. Some successive decrease in the exit volume (in spite of an increase in input) indicates that the roadway has reached its capacity. The plots made relating speed and flow for all upgrades ( $2 \%$ to $6 \%$ ) on the same set of axes are shown in Fig. 3. It can be seen that the developed speed-flow relationships follow the well established trend establishing the validity of the model to simulate heterogeneous traffic flow on different upgrades of magnitudes varying from $2 \%$ to $6 \%$. The capacity values of $8.75 \mathrm{~m}$ wide roads having upgrades of a magnitude of $2 \%, 3 \%, 4 \%, 5 \%$ and $6 \%$ at a negotiated distance of $1600 \mathrm{~m}$ for the representative traffic composition considered are found to be 1360, 1210, 1120, 1050 and 1010 vehicles/h respectively.

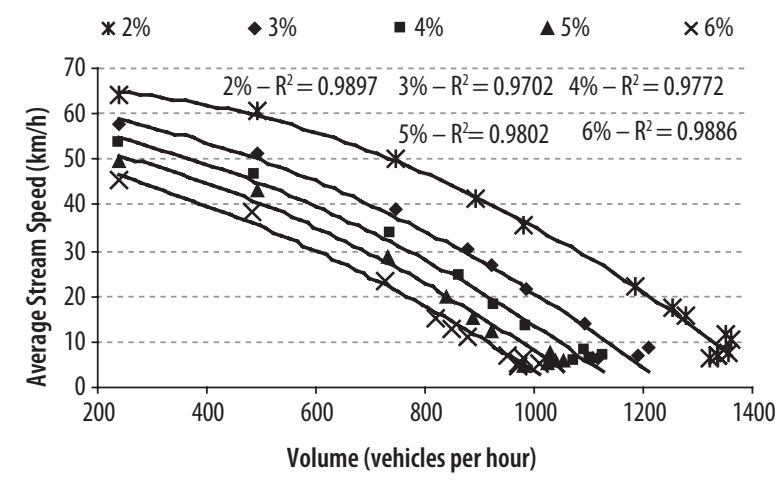

Fig. 3. Speed-volume relationships on upgrades

\subsection{Speed-Distance Profiles for Different Vehicle Types}

Speed-distance relationships for different types of vehicles on grades can be developed by simulating heterogeneous traffic flow on the chosen roadway with a specified gradient and noting down a change in the speed of vehicles at regular intervals over space while the vehicles negotiate the upgrade. For the purpose of simulation, the volume level corresponding to the Volume-to-Capacity $(\mathrm{V} / \mathrm{C})$ ratio of 0.5 (normally used as design service volume in India) was considered for developing speed-distance curves for different vehicle categories along different grades. Free speed values for different vehicle categories, traffic composition and estimated acceleration rates for different vehicle categories at different speed ranges were given as input to the simulation model for simulating traffic flow along different grades ranging from $2 \%$ to $6 \%$. The total length of road stretch, for simulation purpose, was taken as $3400 \mathrm{~m}$. The middle $3000 \mathrm{~m}$ length of the simulation stretch was used to collect data on the simulated average speed for each vehicle category at every $200 \mathrm{~m}$ interval. The simulation model was run with three random number seeds and the average of the three runs was taken as the final output of the model. Speed-distance relationships were thus developed for different vehicle categories for each different grade. The relationships thus, obtained in re- spect of buses, trucks, light commercial vehicles, cars, motorised three-wheelers and motorized two-wheelers are depicted in Figs 4-9, respectively. The figures display that vehicle performance (speed reduction) pertaining to various grades is different across different vehicle categories. In case of heavy vehicles such as buses, trucks and light commercial vehicles having lower power-toweight ratio, there is a significant reduction in speed, whereas for other smaller vehicles such as cars, motorised three-wheelers and motorized two-wheelers having higher power-to-weight ratio, there is a relatively lesser reduction in speed. It can also be noted that there is a significant speed reduction in all upgrades up to a distance of $1600 \mathrm{~m}$ beyond which the speed-distance curve is relatively flatter and indicates that there is no significant speed reduction beyond that point.

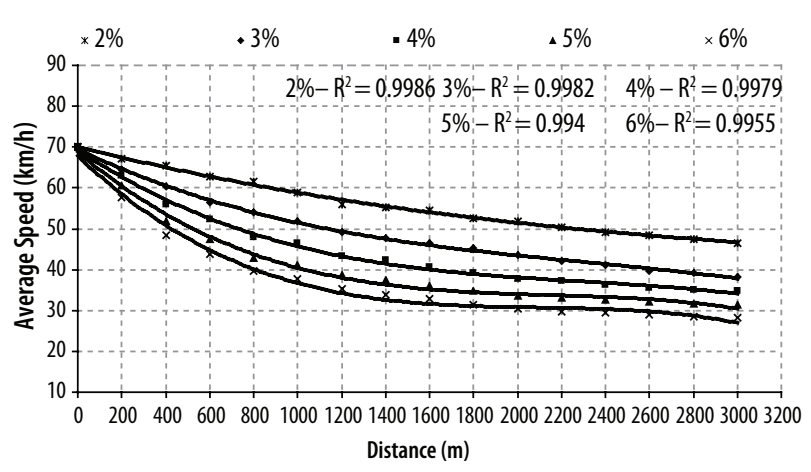

Fig. 4. Speed-distance profiles for buses on upgrades

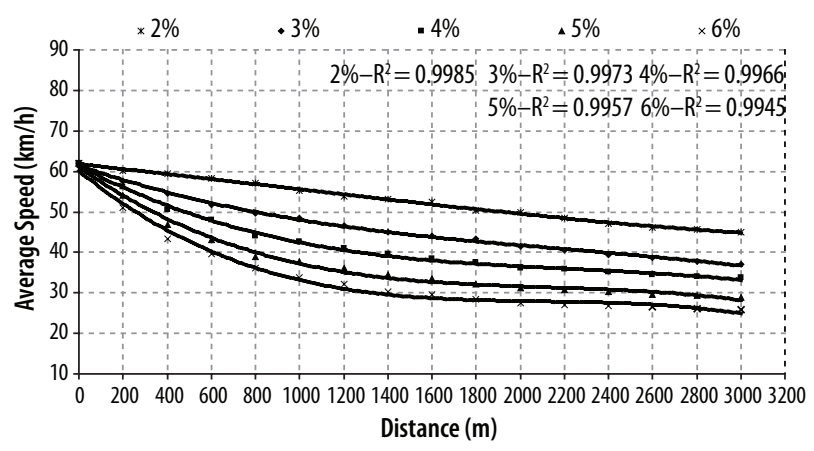

Fig. 5. Speed-distance profiles for trucks on upgrades

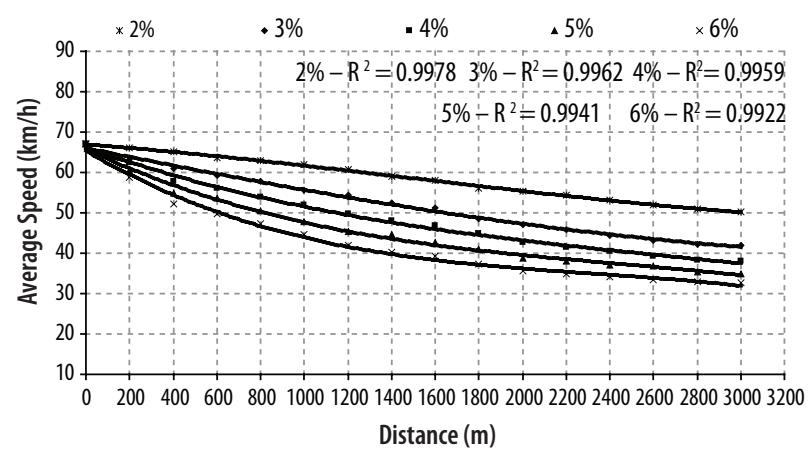

Fig. 6. Speed-distance profiles for light commercial vehicles on upgrades 


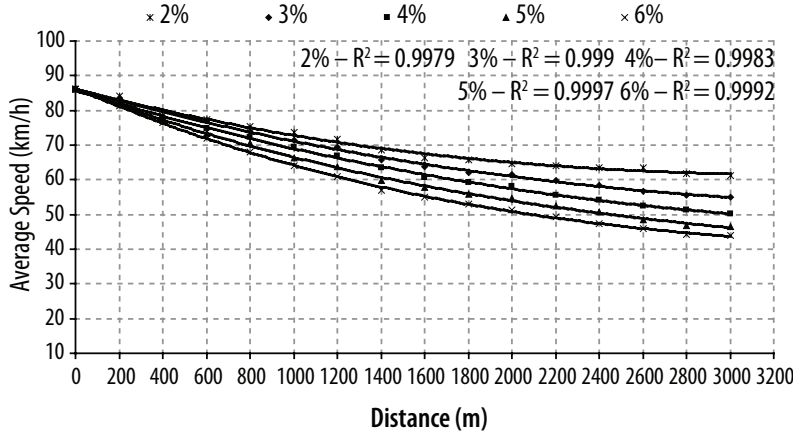

Fig. 7. Speed-distance profiles for cars on upgrades

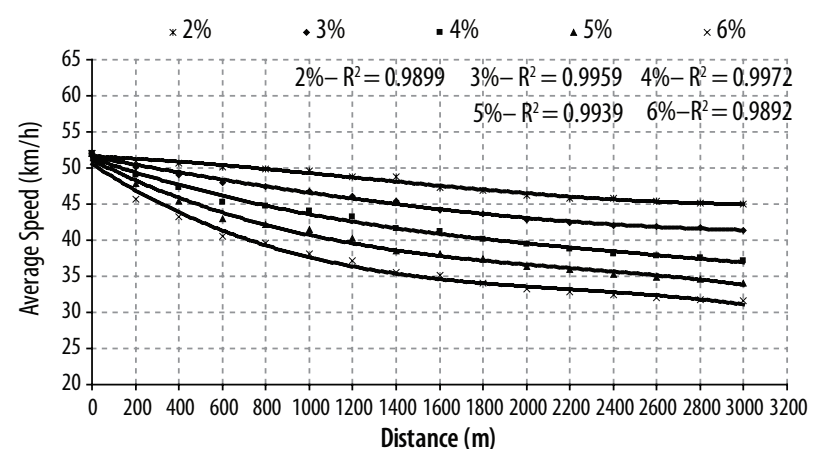

Fig. 8. Speed-distance profiles for motorised three-wheelers on upgrades

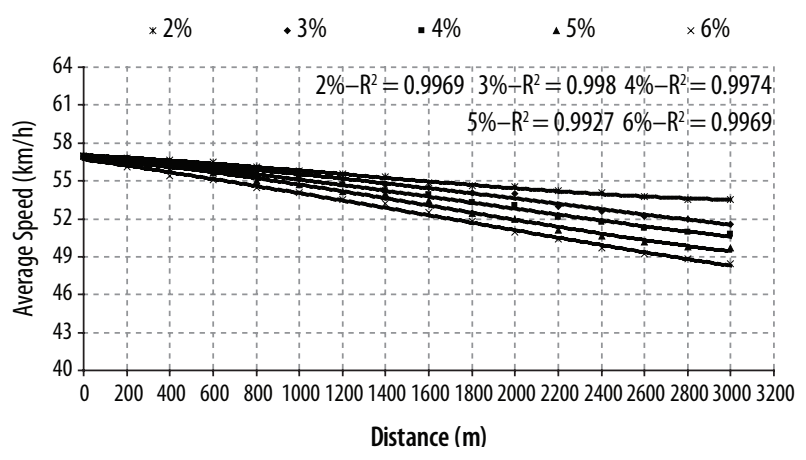

Fig. 9. Speed-distance profiles for motorised two-wheelers on upgrades

\section{Findings}

The following points are the most important findings of this study:

1. The validation results of the simulation model of heterogeneous traffic flow indicate that the model is capable of replicating heterogeneous traffic flow on intercity roads having upgrades of different magnitudes to a highly satisfactory extent.

2. From the speed-volume curves developed using the simulation model, it has been found out that for the representative traffic composition, the capacities of four-lane divided ( $8.75 \mathrm{~m}$ wide) roads having upgrades of the magnitudes of $2 \%, 3 \%$, $4 \%, 5 \%$ and $6 \%$ for one direction of the traffic flow of the section at $1600 \mathrm{~m}$ from the start of the grade, are found to be 1360, 1210, 1120, 1050 and 1010 vehicles/h respectively.
3. From the speed-distance profiles developed for different vehicle types, it has been discovered that the rate of speed reduction in the vehicles, on upgrades, will vary based on the type of a vehicle and it is a function of a magnitude of an upgrade and the power-to-weight ratio of the vehicle.

4. Based on the simulation experiments conducted for developing speed-distance profiles for each type of the vehicle, it was established that the effect of an upgrade on vehicle performance (speed) may not be significant beyond a length of $1600 \mathrm{~m}$.

5. The developed speed-volume and speed-distance relationships provide the basis for estimating Passenger-Car-Unit (PCU) values of vehicles with due consideration to upgrades and their lengths. Thus, through this study, the problem of measuring the volume of heterogeneous traffic on upgrades can be addressed by converting different types of vehicles into equivalent passenger cars and expressing the volume in terms of $\mathrm{PCU} / \mathrm{h}$.

\section{References}

A Policy on Geometric Design of Highways and Streets. 2004. American Association of State Highway and Transportation Officials $896 \mathrm{p}$.

Akgüngör, A. P. 2008a. A new delay parameter dependent on variable analysis periods at signalized intersections. Part 1: Model development, Transport 23(1): 31-36. doi:10.3846/1648-4142.2008.23.31-36

Akgüngör, A. P. 2008b. A new delay parameter dependent on variable analysis periods at signalized intersections. Part 2: Validation and application, Transport 23(2): 91-94. doi:10.3846/1648-4142.2008.23.31-36

Antov, D.; Abel, K.; Sürje, P.; Rõuk, H.; Rõivas, T. 2009. Speed reduction effects of urban roundabouts, The Baltic Journal of Road and Bridge Engineering 4(1): 22-26. doi:10.3846/1822-427X.2009.4.22-26

Arasan, V. T.; Koshy, R. Z. 2005. Methodology for modeling highly heterogeneous traffic flow, Journal of Transportation Engineering - ASCE 131(7): 544-551. doi:10.1061/(ASCE)0733-947X(2005)131:7(544)

Archilla, A. R.; Fernandez De Cieza, A. O. 1996. Truck performance on Argentinean highways, Transportation Research Record: Journal of the Transportation Research Board 1555: 114-123. doi:10.3141/1555-15

Bazaras, J.; Jablonskyte, J.; Jotautienè, E. 2008. Interdependence of noise and traffic flow, Transport 23(1): 67-72. doi:10.3846/1648-4142.2008.23.67-72

Beljatynskij, A.; Kuzhel, N.; Prentkovskis, O.; Bakulich, O.; Klimenko, I. 2009. The criteria describing the need for highway reconstruction based on the theory of traffic flows and repay time, Transport 24(4): 308-317. doi:10.3846/1648-4142.2009.24.308-317

Bennett, C. R.; Greenwood, I. D. 2001. Modelling Road User and Environmental Effects in HDM-4. Volume 7. The highway development and management series. 374 p. Available from Internet: <www.romdas.com/projects/hdm-4/01-0111_rue_book_final.pdf $>$.

Berezhnoy, A.; Grakovsky, A.; Nesterov, A. 2007. The Green Wave mode production on the two-lane highways dur- 
ing the construction works time period, Transport 22(4): 263-268.

Bester, C. J. 2000. Truck speed profiles, Transportation Research Record: Journal of the Transportation Research Board 1701: 111-115. doi:10.3141/1701-14

Bonzani, I. 2007. Hyperbolicity analysis of a class of dynamical systems modeling traffic flow, Applied Mathematics Letters 20(8): 933-937. doi:10.1016/j.aml.2006.06.022

Chandra, S.; Goyal, N. K. 2001. Effect of grade on capacity of two-lane road, Highway Research Bulletin, Indian Roads Congress 64: 77-86.

Gillespie, T. D. 1985. Methods for predicting truck speed loss on grades. Final Report. Contact No DTFHGI-83-C-00046. Available from Internet: <http://deepblue.lib.umich.edu/ bitstream/2027.42/137/2/73427.0001.001.pdf >.

Gowri, A.; Sivanandan, R. 2008. Evaluation of left turn channelization at a signalized intersection under heterogeneous traffic conditions, Transport 23(3): 221-229. doi:10.3846/1648-4142.2008.23.221-229

Gražulevičiene, R.; Bendokienė, I. 2009. Influence of truck traffic on acoustic pollution in Kaunas districts crossed by highways, Journal of Environmental Engineering and Landscape Management 17(4): 198-204. doi:10.3846/1648-6897.2009.17.198-204

Helbing, D.; Greiner, A. 1997. Modeling and simulation of multi-lane traffic flow, Physical Review E 55(5): 5498-5508. doi:10.1103/PhysRevE.55.5498

Jakimavičius, M.; Burinskiené, M. 2007. Automobile transport system analysis and ranking in Lithuanian administrative regions, Transport 22(3): 214-220.

Jakimavičius, M.; Burinskienè, M. 2009. A GIS and multi-criteria-based analysis and ranking of transportation zones of Vilnius city, Technological and Economic Development of Economy 15(1): 39-48.

doi:10.3846/1392-8619.2009.15.39-48

Junevičius, R.; Bogdevičius, M. 2007. Determination of traffic flow parameters in different traffic flow interaction cases, Transport 22(3): 236-239.

Junevičius, R.; Bogdevičius, M. 2009. Mathematical modelling of network traffic flow, Transport 24(4): 333-338. doi:10.3846/1648-4142.2009.24.333-338

Kadiyali, L. R.; Viswanathan, E. Bajaj, J. C.; Bhandari, N. K. 1982. Rolling resistance and air resistance factors for Indian road and vehicle conditions, Highway Research Bulletin, Indian Roads Congress 19: 46-58.

Kadiyali, L. R.; Viswanathan, E.; Gupta, R. K. 1981. Free speeds of vehicles in Indian roads, Journal of Indian Road Congress 165(1): 387-457.

Kerner, B. S.; Klenov, S. L. 2006. Deterministic microscopic three-phase traffic flow models, Journal of Physics A: Mathematical and General 39(8): 1775-1809. doi:10.1088/0305-4470/39/8/002

Khan, S. I.; Maini, P. 2000. Modeling heterogeneous traffic flow, Transportation Research Record: Journal of the Transportation Research Board 1678: 234-241. doi:10.3141/1678-28

Kumar, V. M.; Rao, S. K. 1996. Simulation modeling of traffic operations on two lane highways, Highway Research Bulletin, Indian Roads Congress 54: 211-236.

Lan, C-J.; Menendez, M. 2003. Truck speed profile models for critical length of grade, Journal of Transportation Engineering - ASCE 129(4): 408-419. doi:10.1061/(ASCE)0733-947X(2003)129:4(408)

Lucic, I. 2001. Truck Modeling Along Grade Sections. Thesis submitted to the Faculty of the Virginia Polytechnic In- stitute and State University in partial fulfillment of the requirements for the degree of Master of Science in Civil and Environmental Engineering. 229 p. Available from Internet: <http://scholar.lib.vt.edu/theses/available/etd05162001-152228/unrestricted/ILucic_Thesis.pdf $>$.

Ramanayya, T. 1988. Highway capacity under mixed traffic conditions, Traffic Engineering and Control 29(5): 284-287.

Yagar, S.; Aerde, M. V. 1983. Geometric and environmental effects on speeds of 2-lane highways, Transportation Research Part A: General 17(4): 315-325. doi:10.1016/0191-2607(83)90094-8

Yousefi, S.; Fathy, M. 2008. Metrics for performance evaluation of safety applications in vehicular ad hoc networks, Transport 23(4): 291-298. doi:10.3846/1648-4142.2008.23.291-298 